\title{
Halitosis: diagnóstico y tratamiento en Atención Primaria
}

\author{
J. Fernández Amézaga, R. Rosanes González \\ Especialistas en Mediana Familiar y Comunitaria. C.S. Coronel de Palma. Móstoles. \\ Madrid
}

\section{RESUMEN}

La halitosis es un motivo de consulta frecuente al que se enfrenta el médico de Atención Primaria. Es un sintoma frecuente de múltiples enfermedades odontológicas, pero se debe plantear un diagnósti co diferencial con otras enfermedades (extraora les, sistémicas, psicológicas), algunas de ellas se veras, que también lo producen. El tratamiento de la halitosis implica unas medidas generales sinto máticas (higiene oral) y el tratamiento específico según la etiología causante. Sus repercusiones so ciales, como el aislamiento, económicas (por el gran consumo de productos de higiene dental que realizan estos pacientes) y sanitarias, por el posi ble retraso en el diagnóstico de una enfermedad grave, nos ha llevado a plantear una revisión ac tualizada sobre el tema.

Palabras clave: Halitosis. Aliento. Enjuague bu cal. Higiene oral.
Halitosis: diagnosis and treatment in Primary Health Care

\begin{abstract}
Halitosis is a frequent complaint at Primary He alth Care. Oral malodor is a common symptom of many mouth diseases, but may also indicates other nonoral sources, even a serious systemic illness. So, treatment of halitosis includes oral hygiene and, ocasionally, an specific treatment directed to underlying cause. This review insists on pertinent diagnosis and treatment of halitosis because its large socioeconomic and health care consequences when diagnosis is delayed.
\end{abstract}

Key words: Halitosis. Mouth breathing. Mouth washes. Oral hygiene.

\section{INTRODUCCIÓN}

La halitosis, definida como olor desagradable procedente del aliento de una persona, es un problema social asociado frecuentemente a una mala higiene bucal o a enfermedades de la cavidad oral, pero también puede indicar enfermedades sistémicas severas que necesitan un diagnóstico y tratamiento específicos. Es un campo desconocido, muchas veces ignorado por los profesionales médicos y odontólogos ${ }^{1}$, con escasos ensayos clínicos disponibles y que tiene gran relevancia socioeconómi- ca (no sólo por los problemas sanitarios implicados, sino también por la gran cantidad de dinero que se gasta en productos para la limpieza oral) ${ }^{2}$.

La mayoría de los adultos sufren halitosis en algún momento de su vida. El odontólogo o el médico de familia suelen ser los primeros profesionales a los que se consulta. Aproximadamente un $30 \%{ }^{3}$ de los pacientes mayores de 60 años han padecido o padecen en algún momento halitosis. Con frecuencia los pacientes con halitosis lo desconocen por la incapacidad de oler el propio aliento, o por la habituación resultante de una exposición mantenida ${ }^{4}$. El 58\% son 
informados por otros, en un $24 \%$ lo han notado ellos mismos también, y en un $18 \% \%^{5}$ (en otras series, hasta el 39\% $)^{6}$ sólo lo notan ellos. Las mujeres dan una puntuación más alta de la propia estimación de halitosis que los hombres y, sin embargo, por estimación objetiva, el nivel de halitosis es más alto entre los varones.

El aliento puede variar por diversos motivos:

-El momento del día: tiene una relación inversa con el flujo de saliva, que disminuye durante la noche.

-El día del mes: empeora días antes y durante la menstruación.

-El aliento es peor al empezar a hablar.

- El olor que se presenta en la consulta puede ser o no el típico por el que acude, tanto en intensidad como en calidad.

El típico paciente que consulta suele ser de clase media-alta, que lo aqueja desde hace años, por lo que ha consultado ya a varios especialistas y ha intentado varios tratamientos. Muchos pacientes sufren más de un diagnóstico o cirugía (endoscopia de senos, amigdalectomía, gastroscopia o broncoscopia) por este motivo.

\section{FISIOPATOLOGÍA}

El mal olor procedente de la cavidad oral se debe a la acción de bacterias localizadas principalmente en el dorso de la lengua (en el 90\% de los casos) y en el surco gingival. La gran extensión lingual y su estructura papilada hace que se retengan en ella gran cantidad de restos de comida y desechos, cuya descomposición por la población microbiana presente, origina el mal olor principalmente mediante la producción de Compuestos Volátiles de Sulfuro (CVS).

En una boca sana, los restos celulares pasan a la saliva y son tragados y digeridos rápidamente, por lo que las bacterias no disponen de tiempo para realizar su acción putrefactiva y no se produce halitosis. La saliva lubrica y oxigena la cavidad oral, y posee propiedades antimicrobianas; por tanto, la cantidad y calidad de la saliva son importantes. Así, en los pacientes con xerostomía, la producción de saliva está disminuida, aumentando la posibilidad de producción de CVS, y con ello el mal olor ${ }^{7}$.

El mal olor se relaciona también con la densidad y características de las bacterias presentes en la lengua y en la cavidad oral. Así, en pacientes con halitosis hay mayor proporción de anaerobios y menor de flora facultativa (presente hasta diez veces más que en una boca sana). Se han identificado varios patógenos causantes de enfermedad periodontal y gingivitis ${ }^{8}$ (treponema denticola, Porphy romonas gingivalis y Bacteroides forsythus) que producen mercaptanos y sulfuros y que se asocian con el nivel de halitosis.

Se han descrito varias sustancias implicadas en la génesis de la halitosis 9 :

-Compuestos volátiles de sulfuro (CVS): Son el resultado de la degradación de proteínas que contienen aminoácidos sulfurados (metionina, cistina y cisteína), procedentes de la exfoliación de células epiteliales humanas, leucocitos y restos de comida, y se incrementan con la presencia de sangrado. También se han encontrado en la degradación de proteínas salivales ${ }^{10}$. Entre estos compuestos se encuentran el metilmercaptano $\left(\mathrm{CH}_{3} \mathrm{SH}\right)$,el sulfuro de hidrógeno $\left(\mathrm{H}_{2} \mathrm{~S}\right)$, el dimetil sulfuro $\left(\mathrm{CH}_{3}\right)_{2} \mathrm{~S}$ y el dimetil disulfuro $\left(\mathrm{CH}_{3}\right)_{2} \mathrm{~S}_{2}$. Aunque muchas bacterias producen sulfuro de hidrógeno, incluso en bocas sanas, la producción de metilmercaptano está restringida a patógenos periodontales, y es el compuesto más íntimamente relacionado con la aparición de halitosis. Numerosos estudios han demostrado que concentraciones muy bajas de estos compuestos son muy tóxicas para el sustrato colágeno de los tejidos conjuntivos, lo que favorece el asentamiento bacteriano 6 . Por tanto, los CVS se asocian no sólo a la halitosis, sino que pueden participar en la patogénesis de la gingivitis y la periodontitis. La higiene oral con cepillado de la lengua disminuye los niveles de CVS en aire espirado.

-Ácidos grasos volátiles de cadena corta (butírico, propiónico y valérico), cuyo papel no está bien establecido.

-Poliaminas: putrescina y cadaverina (procedente de la decarboxilación de lisina).

\section{ETIOLOGÍA}

Miyazaki estableció una clasificación sencilla de la halitosis en relación con los procedimientos terapéuticos que precisan, y que incluye las causas de origen psicógeno. Así, incluye las siguientes categorías: halitosis verdadera (fisiológica o patológica), pseudohalitosis (no se objetiva por ningún método pero el paciente percibe de forma subjetiva mal aliento) y halitofobia (paciente tratado de halitosis verdadera o pseudohalitosis que cree que sigue padeciendo halitosis) ${ }^{11,12}$ (Tabla I).

\section{HALITOSIS VERDADERA}

\section{Halitosis fisiológica (factores orales no patológicos)}

-Aliento matutino (morning breath): durante el sueño el flujo de saliva disminuye, no produciéndose el efecto detergente, y queda estancada. Esto facilita el crecimiento incontrolado de bacterias gram negativas y anaerobias, que producen un gas 


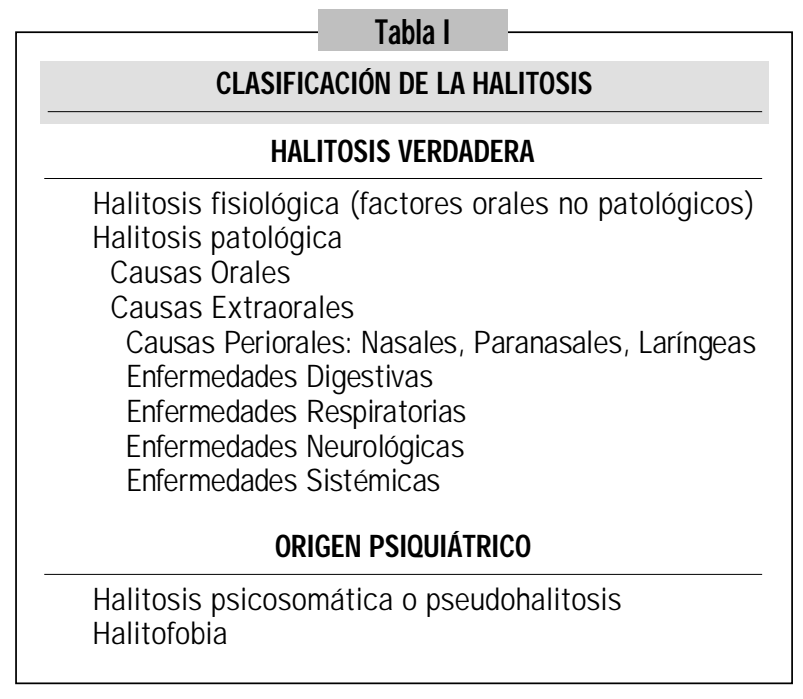

maloliente y putrefacción de ácidos con la posterior producción de productos sulfurados.

- Edad: la calidad del aliento cambia con la edad. Desde la adolescencia a la media edad se hace progresivamente más áspero. En los ancianos los cambios regresivos de las glándulas salivares, afectan a la calidad y cantidad de saliva, incluso con buena higiene dental. El aliento de los ancianos tiende a ser intenso y desagradable.

-Prótesis dentarias: dentaduras, puentes u ortodoncias pueden acumular restos de comida. Estas prótesis deben extraerse y ser limpiadas una vez al día o por un dentista periódicamente. Si se deja puesta una dentadura durante toda la noche, se produce un olor característico dulzón pero desagradable fácilmente reconocible.

- Saliva: el nivel de halitosis es inversamente proporcional al flujo de saliva. La masticación aumenta el flujo de saliva, lo que produce una limpieza de la cavidad oral y se reduce el mal olor. La xerostomía o boca seca causada por el sueño, tras largas conversaciones, por efecto secundario de medicación o por respiración nasal, también contribuye al mal olor. La xerostomía crónica favorece las caries, infecciones, deshidratación y atrofia de las mucosas, y provoca acidificación de la saliva, que facilita el sobrecrecimiento bacteriano, con incremento del porcentaje de gram negativos.

- Tabaco: crea un aliento característico, que incluso puede durar más de un día después de fumar. A veces es usado para enmascarar una halitosis. También se observa aliento de fumador en los fumadores pasivos.

- Hambre: el ayuno puede ser causa de halitosis. Los pacientes que se saltan una comida o que realizan una dieta hipocalórica tienen mayor nivel de halitosis.

-Comida: ciertos metabolitos procedentes de la ingesta pueden absorberse a nivel gastrointestinal ${ }^{13}$, pasan a la circulación, se metabolizan en mucosa intestinal e hígado y se expulsan por los pulmones, como en el caso de la cebolla, el ajo, el pastrami o el alcohol. Los pulmones también excretan los productos del metabolismo de las proteínas y de las grasas, por eso los comedores de carne tienen peor aliento que los vegetarianos. Por otro lado, el contenido gástrico puede manifestarse al exterior a través de un eructo o un vómito. En estos casos es pasajero y responde bien a los métodos de higiene oral habitual.

\section{Halitosis patológica}

\section{Causas orales}

Enfermedad periodontal, estomatitis, faringitis, tumores. En un 85-90\% de los pacientes con halitosis (tanto fisiológica como patológica), el olor se origina en la cavidad oral (14). El mal olor que procede del efecto de las bacterias de la boca, es producido por la putrefacción por gram negativos o por la proteolisis de los gram positivos.

- Higiene oral deficiente, con caries, placa dentaria (sarro) y partículas de comida que permiten el crecimiento bacteriano. Una caries simple no tiene por qué producir olor, pero sí puede originarlo una caries de gran tamaño con acúmulo de comida. Cualquier lugar donde exista acumulación y putrefacción puede ser origen de halitosis: lengua, espacios interdentarios, área subgingival, abscesos. La lengua es la localización de la mayor parte de las bacterias anaerobias en la boca, y producen la mayoría del mal olor. El origen lingual de la halitosis es el más frecuente en caso de ausencia de enfermedad periodontal.

-Reconstrucciones dentales deterioradas (puentes, dentaduras postizas, materiales protésicos).

-Enfermedad crónica periodontal y gingivitis: es la causa más frecuente, pero un importante porcentaje de pacientes con halitosis no la padecen. La lengua puede oler peor si existe enfermedad periodontal. Los tres patógenos periodontales (trepone ma denticola, porphiromas gingivalis y bacteroides forsythus) están asociados con el nivel de halitosis de la boca. Se produce por el deposito de microorganismos orales en la placa de los dientes o en la bolsa periodontal. La presencia de inflamación activa y hemorragia acentúan el proceso de putrefacción.

-Absceso dentario y fístula oro-antral.

-Gingivitis ulcerativa necrotizante o infección de Vincent: produce un típico olor metálico. Evoluciona a una rápida gangrena de tejidos orales y faciales en personas debilitadas e inmunodeprimidas. 
-Estomatitis y glositis resultante de enfermedad sistémica subyacente, gingivoestomatitis herpética, difteria, herpangina, por medicación o por déficit vitamínico. El mal olor se origina por las fisuras o tejidos desvitalizados y disminución del flujo salival.

-Causas ulcerativas: pénfigo, penfigoide, úlceras traumáticas o aftosas, infecciosas.

-Candidiasis oral: por el cambio de flora. Suele suceder en casos de infección por HIV, cáncer, diabetes, xerostomía, por uso crónico de antibióticos o corticoides inhalados.

-Faringe: infecciones víricas, bacterianas o fúngicas (herpangina, difteria, candidiasis, mononucleosis, estreptococo,...). Úlceras. Cáncer faríngeo primario.

-Disfunción parotídea: está asociado a diferentes situaciones, como la parotiditis vírica o bacteriana, absceso parotídeo, sialolitiasis, tumor parotídeo o reacción medicamentosa, así como a enfermedades sistémicas: diabetes, alcoholismo, malnutrición, embarazo, sarcoidosis, leucemia, tuberculosis, enfermedad de Hodgkin o herpes.

- Amígdalas: como causa de halitosis crónica esta discutido. Existe una halitosis transitoria en la amigdalitis aguda. Ocasionalmente al comprimir una amígdala de aspecto normal, emite un exudado de olor fétido. En las criptas de las amígdalas con amigdalitis folicular crónica se puede ir acumulando secreción en forma de pequeños trozos de milímetros de diámetro; si se presionan tienen un olor pestilente, pero no parecen ser el origen de la halitosis.

-Fármacos: hay medicaciones que producen xerostomía, principalmente en ancianos, como los anticolinérgicos. Los antineoplásicos favorecen la candidiasis oral, el sangrado gingival y las úlceras orales. Las fenotiacidas producen una lengua vellosa que facilita la acumulación de comida y bacterias. Otras medicaciones que causan halitosis son los compuestos iodados, nitrato de amilo, antianginosos (dinitrato de isosorbide), antihipertensivos, antihistamínicos, ansiolíticos, antipsicóticos y antidepresivos.

-Necrosis por radioterapia y quimioterapia en pacientes con neoplasias.

\section{Causas extraorales}

La ausencia de una etiología oral clara debe hacernos considerar la posibilidad de etiología orgánica a otros niveles.

\section{Causas periorales: nasal, paranasales, laríngeas}

-Nasales: Si el olor que sale por la nariz es peor que el procedente de la boca. Puede ser indicativo de infecciones, como sinusitis, o problemas que afectan al aire espirado o a secreciones mucosas, como en los pólipos. En la rinitis atrófica o medicamentosa la alteración de la mucosa favorece el crecimiento bacteriano y el mal olor. Otras causas son: atresia coanal unilateral o tumores nasales, ocena, cuerpo extraño en la fosa nasal cuyo olor recuerda al queso (típico de niños y pacientes con retraso mental: huesos, frutos secos, bolitas, piezas de juguetes, etc., que inducen una respuesta inflamatoria y pueden sobreinfectarse con facilidad).

- Sinusitis crónica, caracterizada por goteo postnasal y tos irritativa.

—Epiglotitis aguda (rara causa de halitosis).

- Anomalías craneofaciales: Paladar hendido.

\section{Enfermedades digestivas}

Es menos frecuente de lo que se piensa. El esófago normalmente está colapsado, aunque ocasionalmente puede dejar escapar olor procedente del estómago, pero es raro que sea de forma permanente.

-Divertículo de Zenker: en la unión de hipofaringe posterior y esófago, se produce una pequeña formación que puede ir acumulando saliva y comi$\mathrm{da}$, que al descomponerse puede producir halitosis. El olor no es continuo y depende del peristaltismo esofágico.

-Personas con dispepsia (gastritis, esofagitis, úlcera péptica), reflujo gastroesofágico o hernia de hiato pueden tener aliento fétido (aunque en caso de reflujo, el olor suele recordar a la comida más recientemente ingerida). Un esfínter esofágico debilitado permite la salida de olores gastrointestinales. La achalasia (trastorno motor consistente en la pérdida o alteración del peristaltismo que favorece la relajación del EEI) puede producir retención de alimento, líquido y saliva, que origina halitosis.

- El bezoar (masa gástrica formada por la compactación de material ingerido) es otra causa a descartar.

- La hemorragia digestiva presenta un aliento a sangre coagulada.

-Infección por Helicobacter Pylori ${ }^{15,16}$ : el papel del HP en la patogenia de la halitosis, sólo o asociado a otras bacterias, viene determinado por la producción de sulfuros u otros gases como el amonio a nivel oral (ya que la placa dentaria es su reservorio), gástrico o intestinal. La erradicación del HP conlleva un descenso de marcadores de halitosis en un $80 \%$ en pacientes dispépticos. El efecto del tratamiento en la erradicación del $H P$ oral está por demostrar.

- Otras causas son el cáncer gástrico, el síndrome de malabsorción o la infección entérica. En el caso de la obstrucción duodenal o la fístula gastro- 
cólica, la halitosis es un síntoma que se resuelve quirúrgicamente.

—Patología de la vesícula biliar.

\section{Enfermedades respiratorias}

Infección pulmonar o bronquial, bronquiectasias, absceso pulmonar por anaerobios, neumonía necrotizante y empiema, tuberculosis y enfermedades malignas. Cuerpos extraños en vías respiratorias pueden acumular bacterias y producir olor pútrido.

\section{Enfermedades neurológicas}

Epilepsia temporal asociada a alucinaciones olfatorias, tumores cerebrales. En estos casos no se objetiva la halitosis.

\section{Enfermedades sistémicas}

-Diabetes mellitus mal controlada: la hiperglucemia produce un aliento dulce, afrutado de acetona por un acúmulo de cuerpos cetónicos en sangre, que se expulsan por los pulmones. Además, estos pacientes presentan mayor susceptibilidad a infecciones orales (candidiasis, úlceras, enfermedad periodontal) y a sequedad oral secundaria a deshidratación.

-Insuficiencia renal: característico olor a orina o amoniaco en el aliento.

-Disfunción hepática severa: típico fetor hepático caracterizado por olor a aminas dulces, que precede al coma hepático. Se relaciona con la expulsión de dimetilsulfuro procedente de la acción bacteriana sobre los aminoacidos azufrados. En la cirrosis el olor es a sangre coagulada y a huevos podridos.

-Diversos tipos de carcinomas: las discrasias sanguíneas ${ }^{17}$ (leucemias, agranulocitosis, anemia aplásica, histiocitosis $\mathrm{X}$, linfogranuloma maligno mediofacial) producen olor a sangre coagulada.

-Enfermedades autoinmunes, como el Síndrome de Sjögren, la artritis reumatoide, lupus eritematoso sistémico y la esclerodermia, pueden producir xerostomía por afectación de las glándulas salivales.

—Desórdenes bioquímicos: la trimetilalaminuria con su característico olor a pescado.

- La fiebre alta y la deshidratación por la disminución del flujo de saliva.

-Deficiencias vitamínicas (vit. A y $\mathrm{B}_{12}$ ) o de minerales ( $\mathrm{Fe}$ o $\mathrm{Zn}$ ) pueden producir xerostomía, favoreciendo las fisuras que a su vez acumulan restos de comida y dan lugar al mal aliento.

-Intoxicaciones por plomo, mercurio, bismuto $\mathrm{y}$ arsenicales ${ }^{17}$.

\section{Origen psiquiátrico}

\section{Halitosis psicosomática o pseudohalitosis}

El paciente percibe un mal olor en su aliento que otros no detectan y no se puede objetivar con las pruebas diagnósticas disponibles. Suelen ser personas con tendencia a auto-observación, autocrítica, con dificultad para expresar emociones. Se vio que en la mayoría de estos casos era debido a una interpretación errónea de las actitudes de otras personas (taparse la nariz, volver la cara, dar un paso atrás) y que interpretan como rechazo a su supuesta halitosis, lo que reforzaría su creencia. Por el contrario, se ha demostrado que estos gestos son accidentales y no tienen relación con el mal aliento ${ }^{18}$.

\section{Halitofobia}

Es un miedo exagerado a sufrir mal aliento: el paciente cree que persiste la halitosis incluso tras tratamiento adecuado. Frecuentemente, evitan actos sociales (fobia social), están preocupados por el aliento continuamente con lavados de boca frecuentes, uso de chicles, caramelos, mantienen una distancia de seguridad al hablar, discuten mucho sobre el tema. En los casos extremos llegan al aislamiento social con interrupción de vida laboral o académica, procedimientos médicos invasivos innecesarios, extracción de todas las piezas dentarias o incluso el suicidio.

Algunos autores creen que esta halitosis imaginaria puede ser un síntoma incluido en varios síndromes psiquiátricos:

-Trastornos de ansiedad: fobia social.

- Trastornos somatoformes: dismorfofobias.

- Trastornos del estado de ánimo: depresión mayor con rasgos psicóticos.

—Trastornos psicóticos: trastorno delirante.

\section{DIAGNÓSTICO DE HALITOSIS}

\section{Objetivación de la halitosis}

La halitosis parece atribuirse a los compuestos volátiles sulfurados, principalmente el metilmercaptano y, en menor medida, el sulfuro de hidrógeno. Existe buena correlación entre la halitosis y el nivel de cadaverina.

Actualmente se emplean principalmente tres métodos para objetivar la halitosis ${ }^{19}$ (Tabla II).

- Características organolépticas determinadas por observador externo: percepción del aliento por parte de un examinador y puntuando según escala de 0 a 5. Para un diagnóstico más preciso, debería reali- 
Tabla II

DIAGNÓSTICO DE LA HALITOSIS

OBJETIVACIÓN DE LA HALITOSIS

Características organolépticas determinadas por observador externo

Cromatografía gaseosa

Monitor Portátil de Sulfuro (Halimeter)

Otros: Test del Aliento, Test del olor de Rosemberg,

Actividad de Ureasa Oral, Oratest

DIAGNÓSTICO DEL ORIGEN DEL MAL OLOR

Oler el aliento procedente de la boca y la nariz

alternativamente

Test de la cuchara

Goteo postnasal

Olor de la dentadura

PAUTA DIAGNÓSTICA

Historia clínica: médica, dental, psicológica

Exploración física completa: cavidad oral y extraoral

Estudios de laboratorio o radiográficos

zarse en dos o tres días diferentes. Esta prueba es especialmente útil cuando se sospecha pseudohalitosis o halitofobia. Evitar comida, bebidas y chicles al menos 2 horas antes de la cita. Evitar tabaco, e ingesta de cebolla, ajo y comidas especiadas las últimas 24 horas. No usar lápiz de labios con olor, aftershave o perfumes el día del estudio, así como tampoco realizarlo mientras se esté tomando antibióticos. El inconveniente es la subjetividad, aunque realizada por profesionales con experiencia presenta resultados equiparables al monitor portátil de sulfuro.

-Cromatografía gaseosa: Es el gold standard, ya que detecta de forma específica los compuestos volátiles de sulfuro, la causa principal de la halitosis. El inconveniente es la voluminosidad del equipo y la necesidad de un operador experimentado, por lo que en la práctica es difícil disponer de él.

- Monitor portátil de sulfuro (halimeter): Analiza el contenido total de sulfuro en aire expirado ( se considera normal por debajo de $200 \mathrm{ppb}$ ). La medida del halimeter se correlaciona con el diagnóstico clínico, el grado de lengua saburral y la profundidad de la bolsa gingival. Son menos específicos para detectar CVS, pero existen equipos portátiles y no necesitan personal experto para su interpretación.

-Otros métodos menos empleados son:

- Test del aliento

- Test del olor de Rosemberg

- Actividad de ureasa oral: raspado de zona posterior del dorso de la lengua con una cucharilla de plástico, y posteriormente se extiende en un test de ureasa.
- Oratest: único test que mide otros gases sulfurados correlacionados con la halitosis.

En resumen, podemos decir que la medida de las características organolépticas del aliento por personal entrenado es el procedimiento más accesible para evaluar el grado de mal olor.

\section{DIAGNÓSTICO DEL ORIGEN DEL MAL OLOR}

Para establecer el origen oral hay varias maniobras:

- Oler el aliento procedente de la boca y la nariz alternativamente orienta sobre el origen del olor. Se pide al paciente que cierre la boca y expulse aire por la nariz: si se detecta mal olor es posible que la causa sea nasofaríngea o sistémica. Si el mal olor se detecta al exhalar aire por la boca, con la nariz tapada, sospechar fuentes orales.

-El olor periodontal procede del área subgingival y del espacio interdental.

- Test de la cuchara: en personas con buena higiene oral, con dientes sanos y salud periodontal, el olor frecuentemente procede de la parte posterior de la lengua. La exploración consiste en el raspado con una cucharilla de plástico en la superficie dorsal de la zona posterior de la lengua. A continuación se compara el olor de la cucharilla con el de toda la boca. En ocasiones se objetiva una cubierta a modo de membrana producida por la placa.

- Goteo postnasal: se ve secreción amarilla en la cucharilla. El goteo es frecuente, y no significa que exista patología. El goteo no huele, pero al depositarse en la lengua se puede pudrir por la acción de la flora de la lengua.

- Olor de la dentadura: una maniobra puede ser guardar la dentadura en una bolsa de plástico durante unos minutos, y oler posteriormente al abrirla.

- Si no se identifica una causa oral, se recomienda pautar una semana con gargarismos con un potente colutorio antibacteriano (clorhexidina, por ejemplo). Si se reduce significativamente el nivel de mal olor, habrá que seguir investigando una causa oral $(20)$.

\section{PAUTA DIAGNÓSTICA}

\section{Historia clínica}

- Historia del consumo de comida, bebidas (alcohol), fármacos, tabaco, etc.

-Centrándose en el propio síntoma de la halitosis: es importante recoger el tiempo de evolución, cómo afecta a su vida diaria y cómo ha sido detectado (por él mismo o su cónyuge, amigos,...). Un olor constante sugiere una enfermedad sistémica o 
de la cavidad oral. Si es intermitente, es más propio de enfermedades digestivas como el reflujo gastroesofágico. Cualquier precipitante o agravante debe ser investigado ${ }^{14}$.

- Historia médica: descartar las etiologías previamente mencionadas. Si se presentan síntomas generales no diagnosticados (pérdida de peso, astenia, anorexia, etc.) debemos descartar enfermedades sistémicas. Indagar clínica digestiva o respiratoria. Preguntar los antecedentes familiares (diabetes, enfermedades autoinmunes,...).

- Historia dental: evaluar el grado de higiene dental y los tratamientos previos realizados para reducir la halitosis es básico para asegurar la buena educación y el mantenimiento de la higiene.

-Historia psicológica: existen cuestionarios (Kawaguchi) ${ }^{21,22}$ para descartar la existencia de halitosis de origen psicógeno, que incluyen preguntas psicosomáticas entre otras de índole médico, pero no se recomienda emplearlos en una primera visita para evitar suspicacias en el paciente. Los pacientes con halitosis verdadera también pueden presentar un cierto componente psicológico.

\section{Exploración física completa}

-Es importante la examinación de la cavidad oral, tanto de dientes como de tejidos blandos incluidos los labios, buscando úlceras producidas por traumatismos, infecciones o neoplasias. Puede llegar a ser necesaria una radiografía para identificar una caries que llega a la pulpa del diente. En la lengua, el espesor de la capa saburral está en relación con el mal olor, siendo ésta la principal causa de mal aliento en ausencia de enfermedad periodontal. Es necesario evaluar la extensión de la placa, la inflamación gingival y la enfermedad periodontal en cada paciente.
- Buscar síntomas y signos de xerostomía: pérdida del sentido del gusto, disfagia, mucosa oral dolorosa y eritematosa, caries excesivas y pérdida de papilas filiformes que originan que la lengua aparezca atrófica, brillante y eritematosa.

-Exploración extraoral: centrarse en posibles infecciones o tumores orofaríngeos, inflamación de las glándulas salivares, secreción de material purulento. La permeabilidad de las fosas nasales se explora al expulsar aire por una fosa nasal cerrando la otra. La rinoscopia anterior y posterior permite detectar goteo postnasal, poliposis, etc.

-Confirmación de la halitosis: es importante la confirmación por algún familiar, por ser más objetivo, informando también sobre su intensidad.

- Estudios de laboratorio o radiográficos: deben estar orientados por la historia clínica o exploración física para identificar la causa: analítica general, RX senos paranasales, TAC de la región mediofacial, laringoscopia indirecta o directa, cultivos microbiológicos,...

Si no se ha identificado causa orgánica, habrá que valorar una posible causa psiquiátrica.

\section{TRATAMIENTO}

El tratamiento para la halitosis se ha establecido en 5 categorías según la etiología, para proporcionar unas guías clínicas de actuación, así como la necesidad de derivación a otro especialista: de TN-1 a TN-5 (del inglés, Treatment Needs). De este modo, la halitosis fisiológica precisa medidas del grupo $\mathrm{TN}-1$, la halitosis secundaria a patología oral (TN-1 y TN-2), y la pseudohalitosis (TN-1 y TN-4) deben ser tratadas por un odontólogo. El tratamiento de la halitosis patológica extraoral (TN-1 y TN-3) debe ser manejada por el médico de familia o especialista, y el de la halitofobia (TN-1 y TN-5) por el médico de familia, psiquiatra o psicólogo ${ }^{11}$ (Tabla III).

Tabla III

CLASIFICACIÓN DE LA HALITOSIS SEGÚN EL TRATAMIENTO PRECISADO (TN-TREATMENT NEEDS) MIYAZAKI

\begin{tabular}{|c|c|c|}
\hline Etiología & $\begin{array}{l}\text { Grupo } \\
\text { Terapéutico }\end{array}$ & Profesionales \\
\hline Halitosis fisiológica & TN-1 & Medidas de higiene general* \\
\hline Halitosis secundaria a patología oral & TN-2 & Odontólogo \\
\hline Halitosis extraoral & TN-3 & Medicina de familia y/ o especialista \\
\hline Pseudohalitosis & TN-4 & Odontólogo y Medicina de familia \\
\hline Halitofobia & TN-5 & Psiquiatría \\
\hline
\end{tabular}

* Las medidas de higiene general (TN-1) se deben aplicar en todos los casos. 


\section{Grupo TN-1}

Los procedimientos incluidos en el grupo $\mathrm{TN}-1$ incluyen las medidas generales de higiene y cuidado de la boca, y son recomendables como medida complementaria en todos los casos:

1. El mejor método es una buena higiene dental y que la dentadura esté en buenas condiciones. A menudo hay una resistencia al uso del hilo dental pero una vez que se relaciona el mal olor con la escasa limpieza (como es oler el hilo dental tras la limpieza), la adherencia mejora, aconsejándose su uso al menos una vez al día. El cepillado de los dientes con pasta fluorada debe realizarse al menos dos veces al día.

La limpieza de la lengua así como del paladar debe ser igualmente una rutina diaria, ya que la región posterior del dorso de la lengua es con frecuencia el origen de la halitosis. Un cepillado vigoroso de la lengua por la noche y por la mañana ayuda a reducir el mal olor matutino. Una lengua sana se caracteriza por su intenso color rosado.

También se deben retirar y limpiar al menos una vez al día las dentaduras postizas y demás materiales protésicos.

Se aconseja una visita semestral al odontólogo.

2. El cambio a una dieta vegetariana especialmente rica en frutas frescas y verdura, baja en grasas y carne, reduce la halitosis. Se recomienda evitar alimentos que producen mal aliento como los ajos, las cebollas o bebidas alcohólicas.

\section{Abstención de tabaco.}

4. Tratamiento de la xerostomía: beber abundante agua, y abandono de las bebidas con cafeína. Si es posible, se recomienda la suspensión de los medicamentos asociados a la xerostomía, y su sustitución por otros alternativos, lo que en ocasiones resulta difícil, especialmente en población geriátrica. La estimulación de la producción salival se puede intentar con caramelos sin azúcar, de menta o limón, y con chicles. Si la xerostomía persiste puede utilizarse la saliva artificial (compuestos de carboximetil celulosa), que es efectiva durante aproximadamente $30 \mathrm{mi}-$ nutos, preferentemente antes de las comidas. En casos extremos, la pilocarpina (agonista colinérgico) a dosis de 5-10 mg/día incrementa el flujo de saliva temporalmente en algunos pacientes con síndrome de Sjögren leve o radioterapia local, pero tiene muchos efectos secundarios.

5. Las pastillas oxidativas de potencia elevada reducen significativamente la halitosis del dorso de la lengua respecto al grupo control y respecto a otros tratamientos como son los chicles o las pastillas de menta. El efecto antiolor puede estar en relación con la actividad del ácido dehidroascórbico, que se genera por la peroxidación de ascorbato presente en estas pastillas ${ }^{23}$.

6. Los chicles también reducen el mal olor, pero se aconseja masticar sólo unos minutos para evitar pro- blemas de la articulación temporomandibular. Su mecanismo se basa en la estimulación del flujo de saliva y la limpieza mecánica. Si no poseen ingredientes activos, a las 3 horas de su uso pierden su efecto.

7. El enmascaramiento de los olores mediante el uso de soluciones de aceite de clorofila o con esencia de galauteria es efectivo durante poco tiempo.

8. Los enjuagues y gargarismos con colutorios eficaces son otra alternativa. El mejor momento de utilizarlos es antes de ir a dormir, ya que los restos del producto quedan en la boca por la noche, que es cuando la actividad bacteriana es mayor, y el flujo de saliva menor. Se debe mantener en la boca durante 30 segundos. Muchos colutorios contienen productos perjudiciales para los tejidos blandos por su efecto irritante, como son el alcohol, el sulfato sódico o agentes oxidantes potentes. Hay escasez de estudios clínicos que comparen la eficacia de los distintos tipos de colutorios.

Los enjuagues son un suplemento a la limpieza mecánica de los dientes, encías y especialmente el dorso de la lengua. Muchos de ellos enmascaran el olor, con un efecto a corto plazo: la mayoría duran menos de 3 horas, y sólo los de clorhexidina y el Listerine ${ }^{\circledR}$ duran entre 3 y 6 horas después de su uso. La prevención del mal olor más de 30 minutos después del enjuague es resultado de los componentes antisépticos, pero no tiene efecto a largo plazo.

Los enjuagues con agua son escasamente eficaces al no tener propiedades antisépticas y arrastrar la saliva.

- Características de algunos colutorios $3,7,24$

- Colutorios con alcohol: pueden tener efectos adversos como sensación dolorosa en la boca o producir sequedad de los tejidos orales (el más frecuente) al modificar la cantidad y calidad de la saliva. No se ha encontrado evidencia de la relación entre enjuagues con alcohol y cáncer de boca.

- Enjuagues enzimáticos libres de alcohol y con enzimas antibacterianas (Biotene ${ }^{\circledR}$ ): las enzimas son la lisozima, la glucosa oxidasa y la lactoperoxidasa que inhiben el crecimiento bacteriano. Es útil para el tratamiento de la xerostomía.

- Colutorios con amonio cuaternario (cloruro de benzalconio) y decapinol (Vigencial ${ }^{\circledR}$ ): los enjuagues con amonios cuaternarios se asocian con disminución de los CVS, siendo beneficiosos para reducir el mal olor.

- Colutorios con peróxido de hidrógeno: por su acción oxidativa, pueden dañar los tejidos blandos.

- Colutorios con zinc: Los colutorios pueden contener citrato de zinc o cloruro de zinc (Regal®, OdontocromilC sulfamida ${ }^{\circledR}$, Odamina ${ }^{\circledR}$, Bucore $g i s($ B). Se ha encontrado una reducción del mal olor bucal en pacientes con buena salud oral al disminuir los CVS durante más de 3 horas. Se ha visto que reduce y mantiene los niveles de CVS por debajo del objetivo terapéutico usándolo por la no- 
che. Los enjuagues con zinc impiden la formación de CVS al combinarse con éstos para formar sulfuros no volátiles que no tienen olor y mantienen sana la mucosa. Poseen menos efectos secundarios.

- Colutorios con clorhexidina: (Hibitane corsodyl dental Perio-Aid®, Periogard clorhexidina $\AA)$ ). Son los más efectivos en la reducción de la placa dentaria y de la gingivitis, pero no existen estudios para el control de la halitosis crónica. Su uso durante seis meses se ha asociado con una disminución en un $50 \%$ de la flora aerobia y anaerobia. Los enjuagues con clorhexidina están recomendados en pacientes debilitados por enfermedades médicas (demencia, ACVA o enfermedades neurológicas) que no puedan cepillarse la boca adecuadamente. Tiene efectos secundarios frecuentes como la decoloración de los dientes, el sabor metálico, el aumento del riesgo de cálculos supragingivales, descamación y lesiones dolorosas (no con concentraciones menores del 0,2\%) gingivitis o desequilibrio de la flora de la cavidad oral, por lo que no es aconsejable su uso frecuente o a largo plazo.

- Compuestos con clorhexidina, xilitol y flúor (Cariax gingival®): actúan como los de clorhexidina sólo en la reducción de la placa.

- Enjuagues con dióxido de cloro: es un potente agente antioxidante. Funciona mejor en un $\mathrm{pH}$ neutro a concentraciones de $2 \mathrm{ppm}$, destruyendo el contenido azufrado por oxidación de las uniones de azufre. Previene la producción de CVS al oxidar a la cisteína y metionina de los productos ingeridos. La estabilización del dióxido de cloro se ha obtenido en la solución de clorato sódico (Co bucal®), pero no se conoce su acción desodorante. Se necesitan más estudios para aconsejar su uso en el tratamiento de la halitosis.

- Triclosan: es un agente antimicrobiano de amplio espectro. Es efectivo contra la mayor parte de las bacterias de la boca. Es seguro para reducir la placa y la gingivitis, pero menos efectivo que la clorhexidina o el cloruro de cetilpiridinio (Tirocetil®). Su efecto se debe a su acción antiinflamatoria. Si se formula junto al sulfato laúrico de sodio (SLS) produce menos lesiones. Su eficacia depende de varios factores: su concentración y su unión a otros componentes; si el disolvente es un aceite vegetal es menos efectivo. Unido al ácido maleico reduce la placa; en un dentífrico con silicona reduce la placa y la gingivitis a largo plazo, con una modificación beneficiosa de la flora, teniendo en cuenta que no existen agentes oportunistas resistentes al triclosan; combinado con zinc, se ha visto que reduce el mal olor en tratamientos a largo plazo, por efecto acumulativo se incrementa el éxito al aumentar el tiempo.

- Combinación de Triclosan-Copolimero-Fluo ruro de sodio: es más efectivo que los colutorios antibacterianos con cloruro de cetilpiridinio o fenoles. Se usa durante 30 segundos cada 8 horas.
- Enjuagues de dos fases: los enjuagues de dos fases aceite-agua están siendo estudiados. En un trabajo se observó que había una reducción significativa del mal olor procedente de toda la boca y de la zona posterior de la lengua por la disminución de las bacterias odoríferas en la lengua ${ }^{6}$. Si contienen cloruro de cetilpiridinio se promueve la unión de los microorganismos a la fase de aceite, pero no hay diferencias en los índices de halitosis aunque sí en el control de la placa. En un estudio comparando la clorhexidina, los enjuagues de dos fases con cloruro de cetilpiridinio y placebo se vio que el más efectivo era la clorhexidina y que ambos reducían los CVS, pero el segundo sin efectos secundarios ${ }^{7}$.

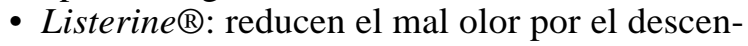
so de la placa bacteriana odorífera. Su reducción del olor era mayor de lo esperado y se atribuyó a su efecto antimicroniano sobre la flora.

9. Remedios alternativos

- Chicles con extracto de té.

-Enjuagues con clorofila añadiendo espirulina y algas con propiedades antimicrobianas.

-Polímero de dióxido de silicona y bicarbonato sódico en comprimidos efervescentes: poseen un efecto de desbridamiento del polímero de silicona $\mathrm{y}$ absorbe a los microorganismos.

\section{Grupo TN-2}

La halitosis patológica de origen oral está producida principalmente por la enfermedad periodontal y por deficiencias en material protésico que pueden contribuir al acúmulo de restos de comida y material de desecho. El tratamiento es odontológico (TN-2).

\section{Grupo TN-3}

La halitosis patológica de causa extraoral debe ser estudiada por el Médico de Familia o derivada al Especialista correspondiente para determinar la causa y aplicar el tratamiento específico para cada enfermedad. Corresponde al grupo terapéutico TN-3.

En pacientes que tienen una infección por Helico bacter Pylori (HP), se ha observado una correlación positiva entre la erradicación bacteriana y la desaparición de la halitosis. Los enjuagues con clorhexidina no son efectivos en HP positivos si no existe erradicación y sí lo son en un $70 \%$ de los HP negativos. No hay diferencia significativa en la actividad oral de la ureasa entre HP positivo y HP negativo. En los pacientes HP negativos no es efectivo el tratamiento erradicador, no desciende los niveles de sulfuros en el aliento, por no actuar sobre las bacterias con actividad putrefactiva oral ${ }^{15}$.

El empleo de antibioterapia sistémica es fundamental en el tratamiento de las causas infecciosas 
tanto de la cavidad oral como amígdalas, senos paranasales, faringe, vías respiratorias, etc.

En la afectación de la mucosa nasal puede ser necesario el empleo de corticoides nasales, así como métodos para el control de los procesos alérgicos (filtros de aire, humidificadores, vacunas,...).

En ocasiones, se requerirá la intervención quirúgi ca (amigdalectomía, extracción de cuerpos extraños en vías aéreas, corrección de anomalías anatómicas).

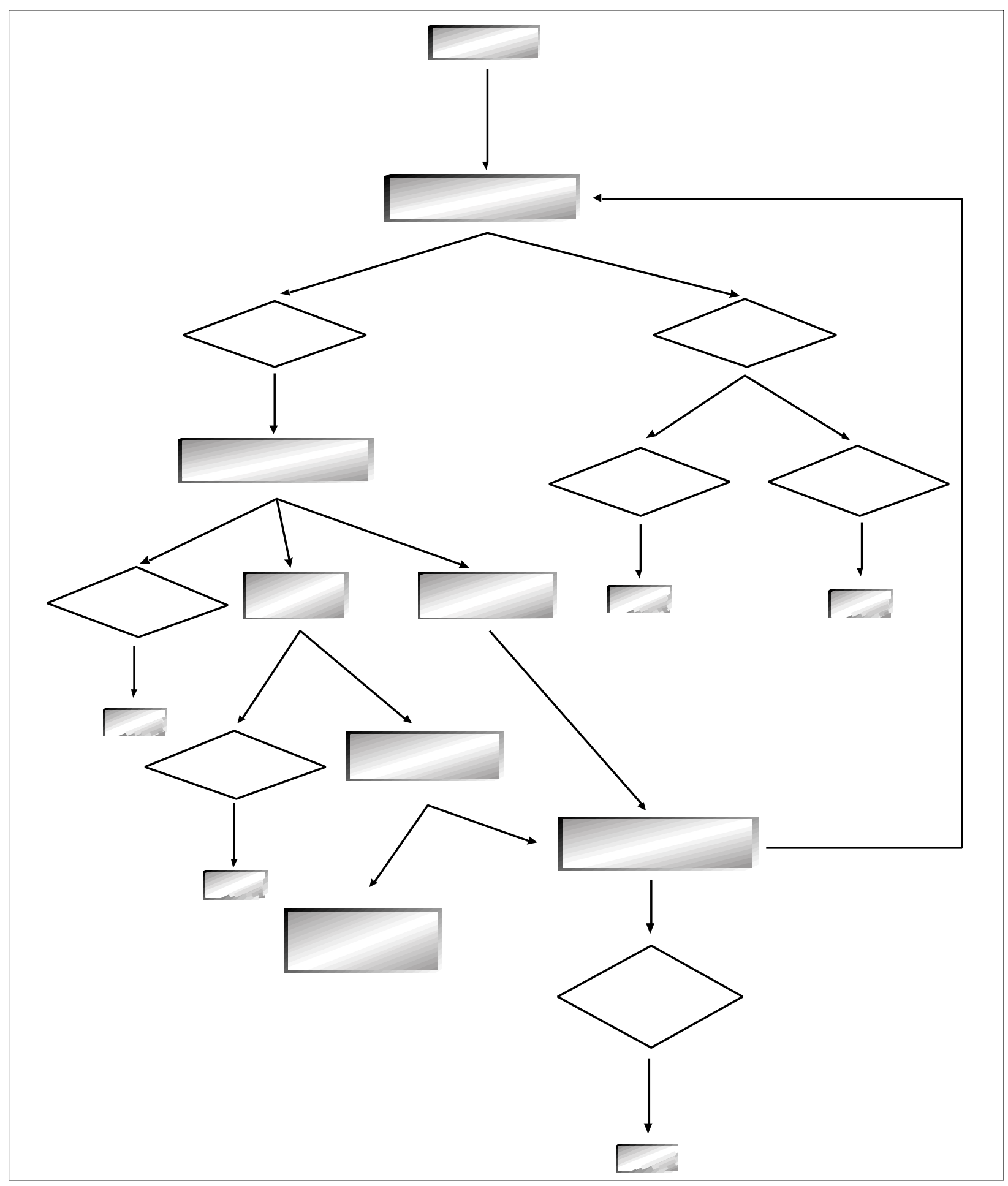




\section{Grupo TN-4}

Los pacientes con pseudohalitosis creen que el comportamiento de otras personas está condicionado por su mal aliento. Estos pacientes deben ser informados con literatura de apoyo, educación sanitaria y explicación del resultado del estudio en su caso que la intensidad de su aliento no está por encima de niveles socialmente aceptados (grupo TN-4). Este paso en el manejo del paciente es el más importante para diferenciar la pseudohalitosis de la halitofobia: los pacientes con pseudohalitosis generalmente responden favorablemente porque son capaces de comprender el consejo médico.

\section{Grupo TN-5}

Los pacientes que padecen halitofobia (no aceptan que su percepción de mal olor es errónea) pertenecen al grupo terapéutico TN-5: necesitan asistencia psicológica especializada (psicólogo, psiquiatra). En este grupo también se incluirían los pacientes con halitosis verdadera tratados con éxito por TN-2 o TN-3 en los que persiste la percepción de halitosis. Los pacientes con halitofobia generalmente rechazan la derivación a un Centro de Salud Mental porque no reconocen que su enfermedad pueda ser psicosomática. Yaegaki ${ }^{18}$ recomienda las siguientes normas para el manejo y derivación de estos pacientes:

- No discutir con el paciente sobre la existencia o no del mal olor.

- Determinar si el paciente es consciente de actitudes o comportamientos de otras personas hacia él.

-Explicarle que esos comportamientos de evitación percibidos no se deben a que padezca halitosis (suceden habitualmente sin ninguna razón).

- Instrucción sobre medidas generales de higiene oral (dientes y lengua), ya que el paciente cree que tiene mal olor y solicita un tratamiento médico.

- Intentar explicar al paciente que no debe juzgar su aliento en relación a los comportamientos percibidos en otras personas, y que si no puede controlar esta sensación, es posible que necesite valoración psicológica especializada para eliminar este hábito. De hecho, en pacientes que eliminan esta sensación, la ansiedad desaparece.

El tratamiento psiquiátrico incluyen la psicoterapia y el tratamiento farmacológico (antidepresi- vos, ansiolíticos o antipsicóticos, como el pimo(ide) ${ }^{25}$.

\section{CONCLUSIONES}

La halitosis es una enfermedad con una prevalencia elevada (más del $50 \%$ de la población), y poco estudiada en nuestras consultas de Atención Primaria. Aunque se la considera más un problema social en relación con una higiene dental deficiente o con enfermedades de la cavidad oral, en ocasiones puede ser la manifestación de patología a otros niveles (perioral, respiratoria, digestiva), o incluso de una enfermedad psiquiátrica o sistémica grave. Por tanto, una primera aproximación debe incluir una historia clínica (dieta, fármacos, hábitos tóxicos, higiene dental, historia médica) y exploración física completas, así como una analítica general.

Como primera medida se recomienda el cepillado de dientes y lengua dos veces al día, hilo dental una vez al día y enjuagues y gargarismos con un colutorio de clorhexidina dos veces al día y reevaluación a los 7 o 14 días. Si no existe mejoría, debemos valorar estudios complementarios para descartar causas orales o extraorales ${ }^{26}$. En la figura 1 se muestra un algoritmo para el diagnóstico y tratamiento de la halitosis.

Se pueden usar actualmente muchos enjuagues para el tratamiento o la prevención de la halitosis, pero dada su evolución crónica, muchos de ellos ofrecen poca o nula ayuda. El más efectivo es la clorhexidina, pero con muchos efectos secundarios. También efectivos y con menos problemas se encuentran el cloruro de zinc, los enjuagues de dos fases agua-aceite con cetilpiridinio o Listerine ${ }^{\circledR}$. Se necesitan más estudios de investigación para llegar a unas técnicas diagnósticas y tratamientos adecuados.

En los casos en que la halitosis es secundaria, es primordial el diagnóstico etiológico y de tratamiento específico.

\section{CORRESPONDENCIA:}

Javier Fernández Amézaga y Rosa Rosanes González

C. S. Coronel de Palma

C/ Coronel de Palma, s/n

28934 Mostoles (Madrid)

e-mail: javiamezaga@hotmail.com 


\section{Bibliografía}

1. Delanghe G, Ghyselen J, Bollen C, van Steenberghe D, Vandekerckove B, Feenstra L. An inventory of patients' response to treatment at a multidisciplinary breath odor clinic. Quintessence Int 1999; 30 (5): 307-10.

2. Van Steenberghe D. The future of breath odor research. [Editorial]. Quintessence Int. 1999; 30 (5): 293.

3. Loesche WJ. The effects of antimicrobial mouthrinses on oral malodor and their status relative to US Food and drug administration regulation. Quintessence Int 1999; 30 (5): 311-8.

4. Rosenberg M, Kozlowsky A, Wind Y, Mindel E. Selfassessment of oral malodor 1 year following initial consultation. Quintessence Int 1999; 30 (5): 324-7.

5. Delanghe G, Ghiselen J Van Steenberghe D, Feenstra L. Multidisciplinary breath-odour clinic [carta]. Lancet. 1997; 350: 187.

6. Ben-Aryeh H, Horowitz G, Nir D, Laufer D. Halitosis: an interdisciplinary approach. Am J Otolaryngol 1998; 19 (1): 8-11.

7. Nachnani S. The effects of oral rinses on halitosis. J Calif Dent Assoc 1997; 25 (2): 145-50.

8. Quirynen M, Van Eldere J, Pauwels M, Bollen C, Van Steenberghe D. In vitro volatile sulfur compound production of oral bacteria in different culture media. Quintessence Int 1999; 30 (5): 351-6.

9. Kleinberg I, Codipilly M. Modeling of the oral malodor system and methods of analysis. Quintessence Int 1999; 30 (5): 357-69.

10. Ratcliff PA, Johnson PW. The relationship between oral malodor, gingivitis and periodontitis. A review. J Periodontol 1999; 70 (5): 485-9.

11. Yaegaki K, Coil JM. Examination, classification and treatment of halitosis; clinical perspectives. J Can Dent Assoc 2000; 66: 257-61.

12. Messadi D. Oral and nonoral sources of halitosis. J Calif Dent Assoc 1997 Feb; 25 (2): 127-31.

13. Hasler W. Garlic breath explained: why brushing your teeth won't help. Gastroenterology 17; (5): 1248-9. Comentario sobre Am J Physiol 1999; 276: 425-30.

14. Rosenberg M. Clinical assessment of bad breath: current concepts. JADA 1996; 127: 475-82.

15. Ierardi E, Amoruso A, La Notte T, Francavila R, Castellaneta S, Marrazza E, et al. Halitosis and helicobacter: A possible relationship. Dig Dis Sci 1998; 43 (12): 2733-7.

16. Tiomny E, Arber N, Moshkowitz M, Peled Y, Gilat T. Halitosis and Helicobacter pylori: a posible link? J Clin Gastroenterol 1992; 15 (3): 236-7.

17. Orive J. Etiología y diagnóstico de la halitosis. Rev Esp Estomatol 1975; 23 (3): 207-10.

18. Yaegaki K, Coil JM. Clinical dilemmas posed by patients with psychosomatic halitosis. Quintessence Int 1999;30 (5): 328-33.

19. Clark GT, Nachnani S, Messadi DV. Detecting and treating oral and nonoral malodors. J Calif Dent Assoc 1997; 25 (2): 133-44.

20. Replogle WH, Beebe D. Halitosis. Am Fam Phy 1996; 53 (4): 1215-23.

21. Kawaguchi Y, Shinada K, Sasaki Y, Nakamura C, Okada S. Clinical application of the "questionnaire for halitosis". J Dent Health 1989; 39: 608-9.

22. Yaegaki K, Coil JM. Clinical application of a questionnaire for diagnosis and treatment of halitosis. Quintessence Int 1999; 30 (5): 302-6.

23. Greenstein RBN, Goldberg S, Marku-cohen S, Steren N, Rosenberg M. Reduction of oral malodor by oxidizing lozenges. J Periodontol 1997; 98 (12): 1176-81.

24. Scully C, El-Maaytah M, Porter SR, Greenman J. Breath odor: etiopathogenesis, assessment and management. Eur J Oral Sci 1997; 105: 287-93

25. Bohn P. Imagined halitosis: a social phobia symptom? J Calif Dent Assoc 1997; 25 (2): 161-4.

26. Neiders M, Ramos B. Operation of bad breath clinics. Quintessence Int 1999; 30 (5): 295-301 (review). 